\title{
Exposure to maltreatment and urban violence in children working on the streets in São Paulo, Brazil: factors associated with street work
}

\author{
Andrea F. Mello, ${ }^{1}$ Mariana R. Maciel, ${ }^{1}$ Victor Fossaluza, ${ }^{2}$ Cristiane S. de Paula,,${ }^{1,3}$ \\ Rodrigo Grassi-Oliveira, ${ }^{4}$ Luciana P. Cavalcante-Nóbrega, ${ }^{1}$ Giuliana C. Cividanes, ${ }^{1}$ Yusaku Soussumi, ${ }^{5}$ \\ Sonia P. Soussumi, ${ }^{5}$ Dirce N. M. Perissinotti, ${ }^{1,5}$ Isabel A. Bordin, ${ }^{1}$ Marcelo F. Mello, ${ }^{1}$ Jair J. Mari ${ }^{1}$ \\ ${ }^{1}$ Department of Psychiatry, Universidade Federal de São Paulo (UNIFESP), São Paulo, SP, Brazil. ${ }^{2}$ Mathematics and Statistics Institute, \\ Universidade Estadual de São Paulo (UNESP), São Paulo, SP, Brazil. ${ }^{3}$ Graduate Program in Developmental Disorders, Universidade \\ Presbiteriana Mackenzie, São Paulo, SP, Brazil. ${ }^{4}$ Graduate Department of Psychology, Pontifícia Universidade Católica do Rio Grande do Sul \\ (PUCRS), Porto Alegre, RS, Brazil. ${ }^{5}$ RUKHA Institute and Center for Studies and Research in Neuropsychoanalysis (CEINP), São Paulo, SP, \\ Brazil.
}

\begin{abstract}
Objective: To quantitatively study the exposure to childhood maltreatment and urban violence in children from families with at least one child working on the streets and to investigate the relationship between these factors and street work.

Methods: Families who participated in a nongovernmental organization (NGO) program to eliminate child labor were included. Data concerning sociodemographic characteristics, punishment methods used in the family environment against the children, five types of abuse and neglect perpetrated by the caregivers, urban violence exposure and family functioning were collected.

Results: The sample included 126 children who were working on the streets and 65 siblings who were not working on the streets. Caregivers reported high levels of severe physical punishment. The children reported high levels of abuse and neglect, and high levels of urban violence exposure. The families showed a predominance of dysfunctional and unsatisfactory relationships. A multiple logistic regression model showed that age older than 12 years and severe physical punishment at home were associated with street work.

Conclusion: Interventions to decrease the risk of child street work should be family-focused and should aim to reduce violence in the family environment.
\end{abstract}

Keywords: Street children; child abuse; child maltreatment; family functioning; urban violence

\section{Introduction}

Child street labor is an important social issue in developing countries, and violence is an important feature in the lives of these children. ${ }^{1}$ The term street children might describe children who live on the street; however, it may also be used to describe those who work on the streets to earn money for their families and return home at the end of the day. The United Nations Children's Fund (UNICEF) named the first group children of the streets and the second group children on the streets. ${ }^{2}$ The present study refers only to the latter group of children.

In 2007, the Brazilian Institute of Geography and Statistics $(\mathrm{IBGE})^{3}$ reported that 2.5 million children between the ages of 5 and 15 years worked, and most of these children (2.3 million) were between the ages of 10 and 15 years. Specifically, $36.5 \%$ of the children worked on farms; $24.5 \%$ worked in stores, workshops, or

Correspondence: Andrea Feijo Mello, PROVE/UNIFESP, Rua Borges Lagoa, 570, $10^{\circ}$ andar, CEP 04038-000, São Paulo, SP, Brazil.

E-mail: amfeijo@uol.com.br

Submitted Jun 09 2013, accepted Dec 042013. factories; and $5.7 \%$ worked on the streets. The remaining children worked in homes, either their own (taking care of younger siblings, cooking, and cleaning), or in other people's homes, as domestic servants (primarily girls). Considering these official data, at least 130,000 children were working on the streets in Brazil, although unofficial data estimated this number to be much higher. For instance, Bezerra et al. ${ }^{4}$ investigated the prevalence of children working on the streets using a capture-recapture strategy in one of the poorest Brazilian states with the worst social indicators in the country. These authors identified that there were 10 times more children who worked on the streets than noted in the official report.

In Brazil, children from low-income and disintegrated families commonly work on the streets, and the wages they earn are sometimes the only source of family income. These children travel to wealthier neighborhoods, either in groups or alone, to wipe windshields, sell candy, collect garbage to recycle, or beg. These children do not regularly attend school, but stay on the streets for many hours during the day and return home to sleep, as well as to provide their parent(s) with money. Younger children usually receive more money than older children, 
which causes parents to send their children to work at an early age. ${ }^{5}$

Some data have shown that Brazilian children on the streets often come from a single-mother-headed family and that poverty, victimization, and a troubled family background are factors associated with working on the streets. ${ }^{6,7}$ Consistent with this finding, international data have shown a similar pattern in other countries. In a 1993 UNICEF survey of 1,000 Ethiopian street children, only $23 \%$ of these children lived with both parents at home. ${ }^{2}$

A Brazilian study of an impoverished sample of children and families from an area of favelas near the city of São Paulo showed that single motherhood was related to increased aggression toward their children. ${ }^{8}$ Further studies have reported that one reason for street children leaving their homes is the number of boyfriends/partners of their mothers that come through the house, which increases levels of abuse. These studies also reported that stepfathers often commit child abuse at higher rates compared to birth fathers. ${ }^{9}$

In addition, Brazilian children and adolescents who work on the streets are frequently reared in a violent environment, surrounded by armed drug gangs who defend their territories with heavy weapons, thereby cutting these children off from the rest of the city. ${ }^{10}$ Although there are some qualitative data regarding children on the streets in Brazil, ${ }^{7,11,12}$ no study has quantitatively addressed the level of violence to which these children have been exposed.

A cross-sectional study performed in India evaluated 200 street children between the ages of 10 and 18 years who worked on the streets. Of these children, $61.8 \%$ reported moderate abuse and $36 \%$ reported severe to very severe forms of abuse. Mild abuse was reported by only $1.6 \%$ of the sample. Verbal and psychological abuse, either on the streets or at home, were the most prevalent forms of maltreatment. Moreover, the level of abuse increased with age and income, and boys were abused more than girls. ${ }^{13}$

Considering that violence is a phenomenon that is extremely prevalent in metropolises and specifically in the city of São Paulo, and that the city has a substantial number of children working on the streets, ${ }^{14}$ the main objective of the present study was to quantitatively evaluate the exposure to childhood maltreatment and urban violence in children from families that had at least one child working on the streets and to investigate the relationship between these factors and street work.

The present study included data regarding the first evaluation of a sample of children that will be followed up for 2 years. The information provided by the present data collection and analyses should help develop family intervention methods focused on specific problem areas.

\section{Methods}

\section{Subjects}

Families that joined a program to eliminate child labor, developed by a nongovernmental organization (NGO) called RUKHA (breath of life in Aramaic), were evaluated.
The children were found by social workers working on the streets of wealthy neighborhoods of the city of São Paulo, and if they agreed, their families were contacted and invited to participate in the NGO program. This was a convenience sample that could only be evaluated due to a partnership between the NGO and Universidade Federal de São Paulo (UNIFESP), Brazil. The families lived in an area of favelas, access to which is controlled by drug dealers. This area, in the South region of the city, is known to be the most dangerous area in São Paulo, with the highest homicide rates in the city. ${ }^{14}$

One hundred families joined the program, which consisted of 211 children between the ages of 7 and 14 years; 191 children from 83 households met the inclusion criteria. The exclusion criteria included mental retardation, untreated mental and neurological disorders, and diseases that could alter the hypothalamic-pituitaryadrenal axis (another arm of the study evaluating stress response). The sample included 126 children who were working on the streets, 65 siblings who were not working on the streets, and 83 caregivers. All of the families had at least one child working on the streets.

The data were collected between October 2008 and March 2009. All of the data were collected at the NGO. Educators from the NGO received training on the instruments and supervised the families and children during data collection to ensure that respondents were able to understand the questions in the self-report forms. As described below, the instruments selected have been adapted and validated in similar Brazilian samples by other Brazilian investigators.

Families were included in this study after the primary caregiver signed an informed consent form, which was approved by the UNIFESP Ethics Committee.

\section{Assessments}

The primary caregivers responded to a questionnaire concerning their social and demographic characteristics and the World Studies of Abuse in the Family Environment (WorldSAFE) Core Questionnaire. Trained psychologists administered the Global Assessment of Relational Functioning Scale. Children completed the Childhood Trauma Questionnaire (CTQ) and the Urban Violence Questionnaire.

(1) A sociodemographic data questionnaire was developed for the present study to collect data on age, sex, level of education, skin color, and religion for children and their parents. Because mixed races comprise a large portion of the Brazilian population, defining people by ethnicity was difficult. For this reason, the sample was divided into three groups according to participant skin color: white, brown, and black. The IBGE also uses this method to collect sociodemographic data from the Brazilian population. $^{3}$

(2) The WorldSAFE Core Questionnaire was developed to investigate intrafamilial violence and associated factors. The instrument examines different child-rearing practices of the mother, her husband/partner, or both over the last 12 months, and includes items concerned 
with the types of parental abusive behaviors usually described in developing countries (e.g., hair pulling, ear twisting, and blows to the head with knuckles). Severe physical punishment included being kicked, choked, smothered, burned, beaten repeatedly, or hit on the buttocks or other parts of the body with an object. The definition used to categorize children between suffering or not suffering from severe physical punishment in the present study was the same definition of severe physical punishment used in a community sample of 14,239 children from 19 communities in six countries. ${ }^{15}$ If any type of the aforementioned punishment methods was reported, then it was considered a positive case of severe physical abuse. A prior Brazilian study used WorldSAFE with a similar sample of impoverished children and validated the instrument. ${ }^{16,17}$

(3) The CTQ is a short-form, self-report, 28-item questionnaire consisting of five subscales with five items each $^{18}$ that has been validated in an adolescent population. ${ }^{19}$ The five subscales are Emotional Abuse, Physical Abuse, Sexual Abuse, Emotional Neglect, and Physical Neglect. The results varied between 5 and 25 . The subscales have cutoff points that further divide the abuse/ neglect category into four additional levels: none, low, moderate, and severe. ${ }^{20}$ Low, moderate, and severe levels of abuse were considered positive in this study. The Brazilian Portuguese version of the $C T Q^{21}$ has been adapted for use with school-aged children from 7 to 11 years old. The adaptation included three phases: construction and language adaptation of a Portuguese version of the CTQ, a pilot study, and administration of the CTQ to 120 children. The adaptation of the scale was based on the same methodology previously used by Kovacs for the construction of the Children Depression Inventory (1985). ${ }^{22}$ Cronbach's alpha showed satisfactory internal consistency of the items (alpha $=0.79$ ) considering the target population.

(4) The Urban Violence Self-report Questionnaire was designed for the present study to collect information concerning exposure to violence or violent situations in the streets. This questionnaire consisted of 17 items that probed the children's exposure to community violence and was based on the 1992 version of Richters and Martinez's instrument. ${ }^{23,24}$ A pilot study was carried out on 16 7-to-14-year-olds from the same living area as the children included in the primary study. The pilot study evaluated whether the children were able to understand and answer the questions properly; however, no reliability or validity assessment was performed. The data were considered a simple description of the violent events reported by the children.

(5) The Global Assessment of Relational Functioning Scale (GARF; Group for Advancement of Psychiatry [GAP]; Committee on the Family, 1996) assesses the functioning of a family on a hypothetical continuum ranging from competent, optimally functioning relationships to disrupted, dysfunctional relationships. This scale is analogous to the Axis-V Global Assessment of Functioning Scale in the DSM-IV, with GARF scores ranging from 0 to 100 . The GARF scale allows clinicians to rate the degree to which a family or another ongoing relational unit meets the affective or instrumental needs of its members in the areas of problem solving, adaptability to stress, maintenance of interpersonal roles, and emotional climate. The scale has been previously used and validated in Brazilian populations. ${ }^{25,26}$

\section{Statistical analyses}

The first step of the analyses was to evaluate the amount of exposure to maltreatment and urban violence and the family functioning of these children. The second step was to divide the data obtained from the children into two groups - children working on the streets and children not working on the streets - to determine whether there were any factors that influenced why some children went to work on the streets whereas others did not.

The nonparametric Mann-Whitney $U$ test was used to compare numerical variables, and the chi-square test, to examine categorical variables at the $5 \%$ significance level.

To confirm the joint effect of critical variables on child maltreatment and work on the street, we used the mixedeffects multiple logistic regression model (MMLR). The variables of interest, including sex, age, and skin color, among others, were considered as fixed factors and the family effect was included in all of the MMLR models as a random factor, allowing consideration of dependence among children in the same family.

The first MMLR analyzed which factors were related to severe physical punishment at home, based on the WorldSAFE total score as a binomial variable (suffering or not suffering severe punishment, according to the definition described in the methods section). The following independent variables were included: child status (working on the streets or not), sex, age (continuous), skin color, and family functioning (continuous). Next, five adjusted models were generated for the five CTQ subscales as primary outcomes to analyze the selfreported measures of abuse/neglect in the family environment. The subscales were treated as binomial variables (suffering or not suffering from abuse). The following independent variables were included in the initial MMLR: child status, sex, age, skin color, and family functioning.

The last MMLR explored the potential factors associated with street work. The variables included in this model were sex, age, skin color, severe physical punishment, presence of the five types of abuse/neglect, exposure to urban violence, and family functioning.

All analyses were performed using the $R$ statistical program. $^{27}$ The Ime4 library (http://Ime4.r-forge.r-project. org) was used for the MMLR.

\section{Results}

Sociodemographic characteristics of children and their caregivers

The sociodemographic characteristics of the children are shown in Table 1. Children on the streets were older and 
Table 1 Social and demographical characteristics of the children

\begin{tabular}{|c|c|c|c|c|c|c|c|}
\hline & \multicolumn{2}{|c|}{ Street children $(n=126)$} & \multicolumn{2}{|c|}{ Siblings $(n=65)$} & \multicolumn{2}{|c|}{ Total $(n=191)$} & \multirow[b]{2}{*}{ p-value* } \\
\hline & Mean & SE & Mean & SE & Mean & SE & \\
\hline Age & 10.93 & 0.184 & 9.68 & 0.249 & 10.50 & 0.154 & 0.0001 \\
\hline \multirow[t]{2}{*}{ Years of study } & 4.39 & 0.174 & 3.30 & 0.221 & 4.03 & 0.142 & 0.0003 \\
\hline & $\mathrm{n}$ & $\%$ & $\mathrm{n}$ & $\%$ & $\mathrm{n}$ & $\%$ & $p$-value \\
\hline School attendance & 110 & 88.0 & 57 & 90.5 & 167 & 88.8 & 0.6109 \\
\hline Grade repetition & 50 & 40.3 & 18 & 27.7 & 68 & 36.0 & 0.0857 \\
\hline Sex & & & & & & & 0.2107 \\
\hline Male & 74 & 58.7 & 32 & 49.2 & 106 & 55.5 & \\
\hline Female & 52 & 41.3 & 33 & 50.8 & 85 & 44.5 & \\
\hline Skin color & & & & & & & 0.0106 \\
\hline White & 21 & 16.9 & 18 & 29.5 & 39 & 21.1 & \\
\hline Brown & 69 & 55.6 & 37 & 60.7 & 106 & 57.3 & \\
\hline Black & 34 & 27.4 & 6 & 9.8 & 40 & 21.6 & \\
\hline Religion & & & & & & & 0.9551 \\
\hline Catholic & 65 & 53.7 & 34 & 56.7 & 99 & 54.7 & \\
\hline Protestant & 39 & 32.2 & 19 & 31.7 & 58 & 32.0 & \\
\hline Atheist & 2 & 1.7 & 1 & 1.7 & 3 & 1.7 & \\
\hline Others & 15 & 12.4 & 6 & 10.0 & 21 & 11.6 & \\
\hline
\end{tabular}

SE $=$ standard error.

* p-value, nonparametric Mann-Whitney $U$ test.

$\dagger p$-value, chi-square test.

had more years of formal schooling. In addition, more black children worked on the streets compared to their siblings $\left(\chi^{2}=9.09, d f=2, p=0.01\right)$.

Regarding the primary caregivers and their sociodemographic characteristics, $92.8 \%$ were mothers, $2.4 \%$ were fathers, $3.6 \%$ were grandmothers, and $2.2 \%$ were aunts. Thus, $97.6 \%$ were women, most of whom were single $(69.9 \%)$. Their mean age was 36 years, and their mean educational attainment was 5.7 years. Twenty of these women were white $(25 \%), 34$ were brown $(42.5 \%)$, and 26 were black $(32.5 \%)$. The mean family income was approximately US $\$ 2,400 /$ year, which was below the minimum wage in Brazil (US\$3,600/year).

\section{Maltreatment and urban violence}

According to the caregivers' responses on the WorldSAFE Core Questionnaire, 112 out of 180 children $(62.2 \%)$ suffered severe physical punishment at home. The percentage of children who received physical punishment was higher among children on the streets $(68.4 \%)$ than among children who were not working on the streets $\left(50.8 \%, \chi^{2}=5.38, p=0.02\right)$.

The CTQ results showed high levels of self-reported abuse and neglect in the family environment for all of the children evaluated; $52.2 \%$ of children reported physical neglect $(54.3 \%$ of children on the streets vs. $48.4 \%$ of their siblings); $51.4 \%$ reported emotional neglect $(51.7 \%$ of children on the streets vs. $50.8 \%$ of their siblings); $33.7 \%$ reported physical abuse (32.8\% of children on the streets vs. $35 \%$ of their siblings); $33 \%$ reported emotional abuse $(31.6 \%$ of children on the streets vs. $33 \%$ of their siblings); and $18 \%$ reported sexual abuse $(15.5 \%$ of children on the streets vs. $22.6 \%$ of their siblings).
All children were exposed to a great amount of violent urban episodes, such as hearing gunshots, being beaten on the streets, seeing people being arrested, and being a victim of police violence. There were only two differences between the groups: a greater percentage of children on the streets reported seeing more people dealing drugs, while a greater percentage of siblings reported seeing people severely beaten.

\section{Family functioning}

The mean GARF score for the families was 49.6 (standard error $[S E]=2.4$ ), indicating that there was a predominance of dysfunctional and unsatisfactory relationships in this sample. All three aspects of family functioning - organization (mean $=50.8$, SE $=2.3$ ), problem solving (mean $=49.6, \mathrm{SE}=2.3$ ), and emotional climate $($ mean $=49.5, \mathrm{SE}=2.6)$ - were equally dysfunctional.

\section{Mixed-effects multiple logistic regression models}

Table 2 shows the results of the logistic regression models.

The first MMLR did not show a correlation between severe physical punishment at home and the analyzed variables.

Next, five adjusted models were generated for the five CTQ subscales as primary outcomes to analyze the selfreported measures of abuse/neglect in the family environment. The subscales were treated as binomial variables (suffering or not suffering from abuse/neglect). The following independent variables were included in the initial MMLR: child status, sex, age, skin color, and family functioning. Our results showed that physical abuse was 
Table 2 Positive results of the logistic regression models*

\begin{tabular}{|c|c|c|c|c|c|}
\hline Dependent & Independent & Estimate & SE & OR & $\mathrm{p}$-value \\
\hline Physical abuse (CTQ) (n=167) & $\begin{array}{c}\text { Intercept } \\
\text { Age }(>12) \\
\text { GARF }\end{array}$ & $\begin{array}{l}2.597 \\
-0.239 \\
-0.023\end{array}$ & $\begin{array}{l}1.272 \\
0.099 \\
0.013\end{array}$ & $\begin{array}{c}13.417 \\
0.788 \\
0.977\end{array}$ & $\begin{array}{l}0.0412 \\
0.0159 \\
0.0862\end{array}$ \\
\hline Sexual abuse (CTQ) $(n=159)$ & $\begin{array}{l}\text { Intercept } \\
\text { Male } \\
\text { GARF }\end{array}$ & $\begin{array}{c}-1.195 \\
0.788 \\
-0.019\end{array}$ & $\begin{array}{l}0.577 \\
0.459 \\
0.011\end{array}$ & $\begin{array}{l}0.303 \\
2.198 \\
0.982\end{array}$ & $\begin{array}{l}\mathbf{0 . 0 3 8 2} \\
0.0862 \\
0.0791\end{array}$ \\
\hline Physical neglect (CTQ) $(n=164)$ & $\begin{array}{c}\text { Intercept } \\
\text { Age }(>12) \\
\text { GARF }\end{array}$ & $\begin{array}{c}-0.449 \\
0.147 \\
-0.021\end{array}$ & $\begin{array}{l}0.929 \\
0.077 \\
0.009\end{array}$ & $\begin{array}{l}0.638 \\
1.158 \\
0.979\end{array}$ & $\begin{array}{l}0.6287 \\
0.0564 \\
\mathbf{0 . 0 1 4 3}\end{array}$ \\
\hline Street work (final model) $(n=175)$ & $\begin{array}{c}\text { Intercept } \\
\text { Age }(>12) \\
\text { SPP } \\
\text { Black }\end{array}$ & $\begin{array}{l}-5.984 \\
0.614 \\
1.150 \\
1.367\end{array}$ & $\begin{array}{l}1.382 \\
0.126 \\
0.583 \\
0.774\end{array}$ & $\begin{array}{l}0.003 \\
1.848 \\
3.159 \\
3.925\end{array}$ & $\begin{array}{l}0.0000 \\
0.0000 \\
0.0485 \\
0.0772\end{array}$ \\
\hline
\end{tabular}

CTQ = Childhood Trauma Questionnaire; GARF = Global Assessment of Relational Functioning Scale; OR = odds ratio; SE = standard error; SPP $=$ severe physical punishment.

$p$-values in bold are significant.

* Including random effect to consider dependence between family members.

correlated to being younger than 12 years old and that physical neglect was related to poor family functioning.

The final MMLR explored the potential factors associated with street work. The variables included in this model were sex, age, skin color, severe physical punishment, presence of the five types of abuse/neglect, exposure to urban violence, and family functioning. The final MMLR showed that age older than 12 years (odds ratio $=1.84$ ) and severe physical punishment at home (odds ratio $=3.15$ ) increased the risk of working on the streets.

\section{Discussion}

In the sample analyzed in this study, exposure to violence was as frequent at home as it was in the neighborhood where these children live. Indeed, these children came from dysfunctional families and were reared in impoverished areas of the city in which violence was a routine experience. We conclude that, in dysfunctional families, when children reach a specific age and if they are subjected to severe physical punishment at home, they will have a greater risk of going to work on the streets.

The present sample also had more boys than girls on the streets. However, unlike other studies, this difference was not statistically significant, ${ }^{2,11,28}$ which may be due to the convenience sampling strategy used in this study. Regarding the mean age of the children (10.5 years), the sample examined in this study was similar to other populations that have been reported in the literature. Previous studies have shown that most children who work on the streets are between the ages of 10 and 14 .

This finding is likely because children younger than 10 do not have the ability to care for themselves on the streets; thus, their caregivers are more fearful of sending them to work alone. Although these families are very dysfunctional, qualitative studies have shown that many of these children's parents also worked on the streets during their own childhood, and perceive the streets as most dangerous for girls and younger children. In addition, adolescents older than 14 do not appeal to passersby as much as younger children do. ${ }^{2,6,11,28}$

The children on the streets in this sample had more years of education compared to their siblings; however, they also had more grade repetition, although the difference was only barely significant. In Brazil, the public school system does not retain students due to their grades, but rather due to school absences, and children have to stay in school for only one period of the day (either from early morning to noon or the entire afternoon). Thus, if children on the streets are retained more often, it is because they do not attend school regularly and are most likely working on the streets all day.

Unfortunately, we found that more black children were working on the streets as compared to their non-black siblings in the same family. Although it is difficult to explain, this finding may suggest some form of prejudice inside the child's home. Brazil is a country of mixed ethnicities, and people find it difficult to determine their own ethnic origins. Even official government statistics use skin color rather than ethnicity to study population demographics. Half of the population is either black or brown $(50.74 \%$ of the total population of $190,755,799)$. According to the IBGE, ${ }^{3}$ black Brazilians have lower educational attainment and family incomes as compared with the rest of the population.

In Brazil, people tend to believe that prejudice is due primarily to poverty rather than skin color; however, qualitative studies have shown that this is an inaccurate assessment. ${ }^{29,30}$ This social issue is very complex, and we cannot establish a clear association between lack of opportunities and an increased risk of black children going to work on the streets. This type of question requires further qualitative studies and was far beyond the scope of our research and objectives at this time.

Concerning the violent factors studied, $62 \%$ of caregivers reported punishing their own children, and mothers were usually the primary caregivers of the children who worked on the streets in this sample population. Children on the streets suffered from more abuse than their 
siblings, as reported by their own caregivers, although regression analysis did not show a correlation between being subjected to severe physical abuse and the variables of interest.

Some hypotheses for future studies can be raised, although the present study design precludes any conclusion as to whether the children in the sample were being beaten before going to the streets. It would be interesting to study whether children developed any type of behavior, after staying on the streets while having to care for themselves in a new and unprotected environment, which increased punishment at home. In addition, it is important to determine whether their homes were always violent or whether some of the children were more prone to respond in a violent manner, and whether their response was dependent on specific characteristics.

Research into the behavior and mental symptoms of these children, as well as their mothers' mental health, may also be helpful in ascertaining whether there was an association between some types of behavior and physical aggression in this specific sample of families.

Most of the investigated women (mothers) were single: only $30 \%$ were living with a partner. This may be related to their high level of violence against their own children, as previously shown in a Brazilian study using a similarly impoverished sample of children and families. ${ }^{8}$ This same pattern was observed in a qualitative study with blended families of homeless youth from Melbourne, Australia. It was reported that particular issues usually arise from a sense of displacement, either of the new member or of the young person. Adolescents feel that the parent has to make a choice between them or the new partner and most mothers became violent in these situations, particularly against their own daughters. Moreover, stepmothers may become violent against girls in blended families. ${ }^{31}$

Furthermore, the rate of violence reported by the caregivers in the present study was much higher than that of another investigation conducted in a similarly underprivileged area of São Paulo state using the same questionnaire (WorldSAFE). The previous study found that the prevalence of severe physical punishment was $20.0 \%{ }^{8}$ Indeed, the present study's rates were also higher than those reported from 19 communities in six countries evaluated by the WorldSAFE study $(n=14,239)$. Importantly, the WorldSAFE study used the same instrument and definition of severe physical punishment as the present investigation. ${ }^{15}$ Finally, a multicenter, international study on physical punishment that included 1,417 children aged 7 to 14 years across nine countries (China, Colombia, Italy, Jordan, Kenya, the Philippines, Sweden, Thailand and the United States) reported that $13 \%$ of girls and $14 \%$ of boys had experienced severe physical punishment. ${ }^{32}$ One can conclude that children from these families with at least one child working on the streets are exposed to extreme levels of physical punishment perpetrated by their caregivers.

Regarding the self-reported measures of abuse/ neglect, this sample of children reported high levels of all types evaluated as compared with data from the community sample. No community study has included quantitative data concerning the amount of abuse/neglect suffered by Brazilian children. For example, an international study analyzing children in Ontario, Canada, with a sample of 9,953 residents aged 15 years and older, found that self-reported physical abuse was present in approximately $10 \%$ of the children ${ }^{33}$; in the present study, however, nearly $35 \%$ of the children reported physical abuse. Gorey \& Leslie ${ }^{34}$ studied the expected prevalence of child abuse by analyzing 16 cross-sectional surveys in North American samples and adjusting for potential responses and measurement biases. They found an expected rate of $14.5 \%$ for females and $7.2 \%$ for males.

Interestingly, $62 \%$ of caregivers in our sample reported punishing their children, and children on the streets were reportedly punished even more than their siblings, while the children self-reported lower levels (approximately $50 \%$ ) of physical abuse. However, the use of an adapted instrument to collect data on child maltreatment may jeopardize our results, and may explain the difference between the mothers' and children's reports. Importantly, there is no other self-report questionnaire that is specific for children and can collect data on abuse/neglect available in Brazil. Moreover, previously published studies have shown that children are able to provide good information regarding maltreatment in clinical and research settings. ${ }^{35}$

Harsh punishment methods are not exclusive to developing countries, although culture can influence the methods used to discipline children. Perhaps in less educated communities, harsh punishment methods are considered an acceptable part of the child education process, and caregivers are not ashamed to declare their use. This may explain the difference found between mothers' and children's reports in the present study. ${ }^{15}$

In addition, children may also be ashamed of being beaten and may thus not report physical abuse, or may perhaps think that some of the behaviors of their parents are acceptable because they are so prevalent, and thus not report these behaviors as aggression. Collection of qualitative data may help further elucidate this finding.

This issue is very serious, because there is sufficient data showing the link between maltreatment and the development of mental disorders, such as depression and posttraumatic stress disorder. ${ }^{36}$ Prospective studies collecting data on the mental health of children at risk are very important to increase knowledge regarding the development of these illnesses. In addition, interventions during child development are also important and should be tested to confirm whether they may be preventative and implemented by government health authorities.

In the present study, $18 \%$ of the children investigated reported sexual abuse, a figure that is higher than the rates expected among the general population. ${ }^{34}$ Regarding child neglect, at least half of the sample reported emotional neglect, physical neglect, or both, which contrasts with the $5.15 \%$ rate of emotional neglect and $17.9 \%$ rate of physical neglect found in a community study of 967 adults from Memphis, Tennessee, using the CTQ. ${ }^{37}$ 
The extremely high levels of punishment reported by caregivers and of self-reported forms of abuse/neglect in the studied sample support the hypothesis that going to work on the streets is, in some way, an attempt to leave a violent family environment. Moreover, going to wealthier neighborhoods may be a strategy for leaving the violent urban environment of the favelas where the children live.

For example, Van den Bree et al. ${ }^{38}$ conducted a longitudinal study of 10,433 British participants and reported that experiences of victimization as well as a troubled family background during adolescence were predictors of homelessness in young adults. Another study of approximately 400 Sudanese children on the streets reported that nearly $50 \%$ of the sample named family disharmony as the reason why they began to work on the streets; subsequently, these youths were frequently exposed to drugs on the streets and abandoned their homes. ${ }^{39}$

Having the opportunity to examine this sample of families with at least one child working on the streets raised the hypothesis that the worst thing for these children would be to stay on the streets all day, which may be attributed to the high level of urban violence exposure. In fact, these children were exposed to a violent family environment and a violent neighborhood environment. Thus, going to the streets of wealthier neighborhoods may be considered as a way out for these children. Unfortunately, this is not a real option, but rather an absence of better alternatives. In previous qualitative studies on street children from Brazil, the children reported that they went to the streets to seek freedom and joy, but also that they could not engage in any type of school activities or sports because of the absence of community programs in their neighborhoods. ${ }^{40,41}$

A limitation of the present study was the use of a crosssectional design and a convenience sample, as it precludes extrapolation of the results to all children working on the streets. In addition, this design did not allow us to drawn any causal inferences. We could not confirm whether the children were leaving their homes because they were subjected to physical abuse or whether working on the streets increased the risk of physical punishment at home.

Moreover, the lack of a control group composed of families from the same community without street-working children limited our study to more descriptive findings. The disproportionate sample size used when comparing children working on the streets and those who were not was another limitation imposed by the use of a convenience sample. Other confounders also influenced our findings. For example, the lack of specific information regarding the caregivers' and children's mental health limited our conclusions, because these factors may have interfered with the pair relationships and with analyses of family functioning.

Further quantitative studies using randomized samples and control groups are required before results can be extrapolated to children on the streets elsewhere in Brazil. This was the first study to quantitatively investigate childhood maltreatment, family functioning, and urban violence in children on the streets in Brazil. The conclusions were consistent with other qualitative studies that addressed previous intervention programs. These studies showed that removal of children from the streets should involve the entire family. Interventions to decrease the risk of child street work should be family-focused to reduce violence in the family environment.

Unfortunately, urgent intervention is needed in this sample of children who were highly exposed to violence in the family environment. Perhaps the only possibility that is feasible and ethical is to remove some children from this family environment. Health providers report such cases to the authorities when confirmed, but the formal child protection system functions poorly and is inefficient. Thus, society must have access to the results of studies with children at risk, so that more people will put pressure on government agencies responsible for the support and protection of children.

Government authorities in Brazil must use the knowledge produced by these studies to develop intervention programs focused on the environment to which these children are exposed and to offer better school programs, create community activities to involve children in healthier behaviors, and improve the family environment (i.e., decreasing punishment, abuse, and neglect). These improvements should help break the cycle of violence to which children on the streets are routinely exposed and reduce the risk of street work.

\section{Acknowledgements}

This research was funded by a grant from Conselho Nacional de Desenvolvimento Científico e Tecnológico (CNPq) (575114/2008-8). AFM has received a scholarship from Coordenação de Aperfeiçoamento de Pessoal de Nível Superior (CAPES) (PNPD 02772/09-4). JJM, MFM and RGO are supported by CNPq.

\section{Disclosure}

The authors report no conflicts of interest.

\section{References}

1 Nada KH, Suliman el DA. Violence, abuse, alcohol and drug use, and sexual behaviors in street children of Greater Cairo and Alexandria Egypt. AIDS. 2010;24:S39-44.

2 Lalor KJ. Street children: a comparative perspective. Child Abuse Negl. 1999;23:759-70.

3 Instituto Brasileiro de Geografia e Estatística (IBGE). Sintese de indicadores socias. Uma análise das condições de vida da população brasileira, 2008 [Internet]. 2009 [cited 2013 Dec 20]. http://www.ibge.gov.br/home/estatistica/populacao/condicaodevida/ indicadoresminimos/sinteseindicsociais2008/indic_sociais2008.pdf

4 Bezerra KF, Gurgel RQ, llozue C, Castaneda DN. Estimating the number of street children and adolescents in two cities of Brazil using capture-recapture. J Paediatr Child Health. 2011;47:524-9.

5 Gontijo D, Medeiros M. [Children and adolescents in street situation: contributions to an understanding of vulnerability and disaffiliation]. Cien Saude Colet. 2009;14:467-75. 
6 Abdelgalil S, Gurgel RG, Theobald S, Cuevas LE. Household and family characteristics of street children in Aracaju, Brazil. Arch Dis Child. 2004;89:817-20.

7 Paludo SS, Koller SH. Toda criança tem família; criança em situação de rua também. Psicol Soc. 2008;20:42-52.

8 Bordin IA, Duarte CS, Peres CA, Nascimento R, Curto BM, Paula CS. Severe physical punishment: risk of mental health problems for poor urban children in Brazil. Bull World Health Organ. 2009;87:33644.

9 Alexandre GC, Nadanovsky P, Moraes CL, Reichenheim M. The presence of a stepfather and child physical abuse, as reported by a sample of Brazilian mothers in Rio de Janeiro. Child Abuse Negl. 2010;34:959-66.

10 Fraser B. Growing up in Rio's favelas. Lancet. 2011;377:1735-6.

11 Raffaelli M, Koller SH, Reppold CT, Kuschick MB, Krum FM, Bandeira DR, et al. Gender differences in Brazilian street youth's family circumstances and experiences on the street. Child Abuse Negl. 2000;24:1431-41.

12 Maciel C, Brito S, Camino L. Explicações das desigualdades sociais: um estudo com meninos em situação de rua de João Pessoa. Psicol Reflex Crit. 199811:209-32.

13 Mathur M, Rathore P, Mathur M. Incidence, type and intensity of abuse in street children in India. Child Abuse Negl. 2009;33:907-13.

14 Prefeitura do Município de São Paulo, Secretaria Municipal da Saúde, Coordenação de Epidemiologia e Informação (CEInfo). Diagnóstico mínimo por coordenadoria regional de saúde. São Paulo: Prefeitura de São Paulo; 2005.

15 Runyan DK, Shankar V, Hassan F, Hunter WM, Jain D, Paula CS, et al. International variations in harsh child discipline. Pediatrics. 2010;126:e701-11.

16 Bordin IA, Paula CS, do Nascimento R, Duarte CS. Severe physical punishment and mental health problems in an economically disadvantaged population of children and adolescents. Rev Bras Psiquiatr. 2006;28:290-6.

17 Curto BM, Paula CS, do Nascimento R, Murray J, Bordin IA. Environmental factors associated with adolescent antisocial behavior in a poor urban community in Brazil. Soc Psychiatry Psychiatr Epidemiol. 2011;46:1221-31.

18 Bernstein DP, Fink L, Handelsman L, Foote J, Lovejoy M, Wenzel K, et al. Initial reliability and validity of a new retrospective measure of child abuse and neglect. Am J Psychiatry. 1994;151:1132-6.

19 Bernstein DP, Ahluvalia T, Pogge D, Handelsman L. Validity of the Childhood Trauma Questionnaire in an adolescent psychiatric population. J Am Acad Child Adolesc Psychiatry. 1997;36:340-8.

20 Paivio SC, Cramer KM. Factor structure and reliability of the Childhood Trauma Questionnaire in a Canadian undergraduate student sample. Child Abuse Negl. 2004;28:889-904.

21 Grassi-Oliveira R, Stein LM, Pezzi JC. [Translation and content validation of the Childhood Trauma Questionnaire into Portuguese language]. Rev Saude Publica. 2006;40:249-55.

22 Soares S. Construção do inventário de maus tratos na infância (CMI). Porto Alegre: Pontifícia Universidade Católica do Rio Grande do Sul; 2011.

23 Richters JE, Martinez P. The NIMH community violence project: I. Children as victims of and witnesses to violence. Psychiatry. 1993;56:7-21
24 Richters JE, Martinez P. Screening survey of children's exposure to community violence. Bethesda: National Institute of Mental Health. 1993.

25 Mello AF, Blay SL, Kohn R. Global Assessment of Relational Functioning Scale (GARF): a validity study in patients with recurrent major depression in Brazil. Transcult Psychiatry. 2007;44:55-64.

26 Falceto OG, Busnello ED, Bozzetti MC. [Validation of diagnostic scales of family functioning for use in primary health care services]. Rev Panam Salud Publica. 2000;7:255-63.

27 R: a language and environment for statistical computing. R Foundation for satistical computing [Internet]. 2010 [cited 2010]. http://www.R-project.org

28 Parker DL. Street children and child labour around the world. Lancet. 2002;360:2067-71.

29 Rosa W. Retrato das desigualdades de gênero e raça. $3^{a}$ ed. Brasília: IPEA; 2008.

30 Camino L, Silva P, Machado A, Pereira C. A face oculta do racismo no Brasil: uma análise psicossociológica [Internet]. Rev Psicol Polít. 2000 [cited 2013 Dec 20]. http://www.fafich.ufmg.br/ psicopol/ pdfv1r1/Leoncio.pdf

31 Mallett S, Rosenthal D. Physically violent mothers are a reason for young people's leaving home. J Interpers Violence. 2009;24:116574.

32 Lansford JE, Alampay LP, Al-Hassan S, Bacchini D, Bombi AS, Bornstein $\mathrm{MH}$, et al. Corporal punishment of children in nine countries as a function of child gender and parent gender. Int $\mathrm{J}$ Pediatr. 2010;2010:672780

33 MacMillan HL, Fleming JE, Trocme N, Boyle MH, Wong M, Racine YA, et al. Prevalence of child physical and sexual abuse in the community. Results from the Ontario Health Supplement. JAMA. 1997;278:131-5.

34 Gorey KM, Leslie DR. The prevalence of child sexual abuse: integrative review adjustment for potential response and measurement biases. Child Abuse Negl. 1997;21:391-8.

35 Sturgess J, Rodger S, Ozanne A. A review of the use of assessment with young self-report children. Brit J Occup Ther. 2002;65:10816.

36 Mello MF, Faria AA, Mello AF, Carpenter LL, Tyrka AR, Price LH. [Childhood maltreatment and adult psychopathology: pathways to hypothalamic-pituitary-adrenal axis dysfunction]. Rev Bras Psiquiatr. 2009;31:S41-8.

37 Scher CD, Forde DR, McQuaid JR, Stein MB. Prevalence and demographic correlates of childhood maltreatment in an adult community sample. Child Abuse Negl. 2004;28:167-80.

38 van den Bree MB, Shelton K, Bonner A, Moss S, Thomas H, Taylor PJ. A longitudinal population-based study of factors in adolescence predicting homelessness in young adulthood. J Adolesc Health. 2009;45:571-8.

39 Plummer ML, Kudrati M, Yousif N. Beggining street life: Factors contributing to children working and living on the streets of Khartoum, Sudan. Children Youth Serv Rev. 2007;29:1520-36.

40 Ribeiro MO. [The street: a deceitful shelter to the children living in it]. Rev Lat Am Enfermagem. 2003;11:622-9.

41 Ferreira FP. Crianças e adolescentes em situação de rua e seus macro determinantes. Saude Soc. 2011;20:338-49. 